\title{
IMUNIDADE RELATIVA À POLIOMIELITE EM CRIANÇAS DE ZERO A DEZ ANOS, APÓS O "QUARTO DIA NACIONAL DE VACINAÇĀO CONTRA POLIOMIELITE" COM A VACINA ORAL TRIVALENTE, TIPO SABIN, EM AREA DA GRANDE SÃO PAULO, SP (BRASIL), 1982
}

\author{
Victório Barbosa * \\ Eliseu Alves Waldman** \\ Mitiko Fujita*** \\ Cecilia Kitamura *** \\ Chang Chung Sing Waldman $* * * *$ \\ José Paulo Gonzaga de Lacerda***
}

\begin{abstract}
BARBOSA, V. et al. Imunidade relativa à poliomielite em crianças de zero a dez anos, após o "Quarto Dia Nacional de Vacinação Contra a Poliomielite" com a vacinação oral trivalente, tipo Sabin, em área da Região da Grande São Paulo, SP (Brasil), 1982. Rev. Saúde públ., S. Paulo, 18:19-29, 1984.
\end{abstract}

RESUMO: Efetuou-se um levantamento soro-epidemiológico, abrangendo 898 crianças, para a verificação da irrunidade aos poliovírus 1,2 e 3 por meio da determinação dos títulos de anticorpos neutralizantes. De 522 crianças, ou seja, de $\mathbf{5 8 , 1} \%$ da população estudada, foi possível a obtenção de informações referentes à situação vacinal a partir de anotações existentes nas próprias Cadernetas de Vacinação. Neste último sub-grupo foi estudado - estado imunitário em relação ao número de doses de vacina oral tipo Sabin recebidas. Os resultados mostraram alta proporção de imunes para os três tipos de poliovirus entre as crianças estudadas, porém também revelaram a existência de lacuna imunitária nos menores de um ano, especialmente no primeiro semestre de vida. Não foram observadas diferenças importantes na proporção de imunes segundo o sorotipo considerado. Salientou-se a recessidade de um alerta constante e permanente em relação à ocorrência de possiveis surtos epidêmicos em segmentos mais vulneráveis da população, particularmente entre crianças menores de 1 ano.

UNITERMOS: Poliomielite. Inquérito soro-epidemiológico. Profilaxia. Vigilância epiđemiológica.

\section{INTRODUÇÃO}

Continuando a sêrie de estudos que vimos fazendo sobre poliomielite, desde $19632,3,4,5,6,17,39$, pretendemos com este trabalho, mais uma vez, contribuir no sentido de proporcionar novos e atuais subsidios para o planejamento, execução e avaliação do comportamento epidemiológico dessa doença na Região da Grande São

* Do Departamento de Epidemiologia da Fac:ldade de Saúde Pública da USP - AJ. Dr. Arnaldo, 715 - 01255 - São Paulo, SP - Brasil.

* Do Departamento de Epidemiologia cla Faculdade de Saúde Pública da USP e do Instituto Adolfo Lutz da Secretaria de Estado da Saúde de São Paula - Av. Dr. Arnaldo, as5 - 01246 - São Paulo, SP - Brasil.

*** Do Instituto Adolfo Lutz da Secretaria de Estado da Saúde de São Paulo.

*** Do Distrito Sanítário de Tucuruvi, da Coordenadoria de Saúde da Comunidałe da Secretaria de Estado da Saúde de São Paulo - Av. Nova Cantareira, 1.463 - 02331 São Paulo, SP - Brasil. 
BARBOSA, V. et al. Imunidade relativa à poliomielite em crianças de zero a dez anos, apos o "Quarto Dia Nacional de Vacinação Contra a Poliomielite" com a vacinaçio oral trivalente, tipo Sabin, em área da Região da Grande São Paulo, SP (Brasil), 1982. Rev. Saúde públ., S. Paulo, 18:19-29, 1984.

Paulo, agora já na fase deveras importante da Vigilância Epidemiológica pós-controle dessa virose.

Os coeficientes de morbidade por poliomielite até $0,1 / 100.000$ habitantes *, verificados na Região da Grande São Paulo, a partir de 1981, alcançados em decorrência das quatro campanhas nacionais de imunização com vacina oral, tipo Sabin, constituem um marco no programa de controle dessa doença na Região (Tabela 1).

As grandes campanhas da vacinação contra a poliomielite, iniciadas, nos países desenvolvidos, há cerca de duas décadas, com a utilização de virus vivo atenuado e, em alguns casos, de virus inativado, seguidas de imunização rotineira dos novos suscetiveis, permitiram o efetivo controle dessa virose, traduzido pela sua virtual eliminação nessas regiões $6.11,15,22$.

A aplicação da mesma estratégia, em nosso pais, tem suscitado dúvidas quanto ao momento adequado à suspensão dessas imunizações em massa - embora o Ministério da Saúde tivesse previsto até 1985 exclusive - e a subseqüente manutenção de baixa incidência da doença apenas por meio da vacinaçăo de rotina. Isto decorre do fato da estrutura epidemiológica para a poliomielite, em nosso meio, ainda propiciar ampla disseminação de seu agente e a ocorrência precoce da infecção $\$, 10,17,28,31,37,39$

O estágio atual do programa de controle da poliomielite no Brasil 31 e, em nosso caso particular, na Região da Grande São Paulo ${ }^{39}$, implica necessariamente na ampliação do elenco de informações suficientes e adequadas à sua vigilância epidemiológica.

Entre os parâmetros a serem incluídos nas análises de seu comportamento epidemiológico, distinguem-se: a distribuição da poliomielite em casos associados, ou não, à vacina oral, tipo Sabin; a ocorrência da doença em imunodeprimidos; os inquéritos referentes à contaminação ambiental pelos seus agentes causais; a pesquisa de residuos de suscetiveis e de fontes de infecção; a distribuição dos casos confirmados, segundo o sorotipo de virus, e, por fim, a diferenciação em estirpes "selvagens" e "vacinais" dos poliovírus isolados de casos paralíticos, de portadores e do meio ambiente $t, 11$.

O presente trabalho estudará o estado imunitário contra a poliomielite, de população da Regiāo da Grande São Paulo, em um grupo de crianças de 0 a 10 anos, em período posterior ass quatro primeiros "Dia Nacional de Vacinação Contra a Poliomielite" com a vacina oral tipo Sabin. Esta pesquisa tem o objetivo de detectar possíveis resíduos de suscetíveis, assim como verificar a proporção de imunes, segundo o número de doses de vacina oral recebidas pelas crianças dessa faixa etária.

\section{MATERIAL E MÉTODOS}

A presente pesquisa foi realizada com crianças residentes na Região da Grande São Paulo, área constituida por 37 municípios, incluindo a capital do Estado de São Paulo, con superfície de $8.053 \mathrm{~km}^{2} \mathrm{e}$ que, conforme o Censo Demográfico de 1980 , apresenta uma população de cerca de 12.500 .000 habitantes, ou seja, aproximada. mente, 50,0\% da população do Estado.

Foram estudadas 898 crianças de 0 a 10 anos de idade, de ambos os sexos, atendidas em Centros de Saúde do Estado localizados na Região da Grande São Paulo e encaminhadas ao Laboratório Central do Instituto Adolfo Lutz para submeterem-se a exames de laboratório que implicassem colheita de amostras de sangue. Uma alíquota dessas amostras era enviada imediatamente ao Serviço de Virologia, do citado Instituto, visando à execução das provas de neutralização para os três tipos de poliovírus.

* Fonte: C.I.S. Centro de Informações de Saúde da Secretaria de Estado da Saúde de São Paulo). 
BARBOSA, $V$. et al. Imunidade relativa à poliomielite em crianças de zero a dez anos, após o "Quarto Dia Nacional de Vacinaçāo Contra a Poliomielite" com a vacinação oral trivalente, tipo Sabin, em área da Regiāo da Grande Sâo Paulo, SP (Brasil), 1982. Rev. Saúde públ., S. Paulo, 18:19-29, 1984.

O presente trabalho foi levado a efeito no perjodo de fevereiro a abril de 1982; portanto, posteriormente aos quatro primeiros "Dia Nacional de Vacinação Contra a Poliomielite", realizados em todo o território brasileiro nos meses de junho e agosto de 1980 e 1981, abrangendo preferencialmente as crianças de 0 a 5 anos.

De 522 crianças, ou seja, de $58,1 \%$ da amostra estudada, foi possivel a obtenção de informações referentes à situação vacinal a partir de anotaçóes existentes nas próprias Cadernetas de Vacinação. Somente nesse grupo foi estudado o estado imunitário em relação ao número de doses de vacina tipo Sabin recebidas.

A técnica utilizada na determinação de anticorpos neutralizantes para os três sorotipos de poliovirus foi a de Rosenbaum e col. ${ }^{32}$, tendo sido por nós apresentada, de forma pormenorizada, em trabalho anterior- mente publicado ${ }^{39}$. Na análise dos resultados, as crianças que não apresentaram anticorpos neutralizantes detectáveis na diluição de 1:8 foram consideradas suscetiveis.

Em relação a renda dos pais, $75,8 \%$ das crianças estudadas apresentavam-na entre 1 e 3 salários mínimos da época. Quanto ao local de residència, 9,1\%, 33,4\% e $46,5 \%$ das crianças moravam, respectivamente, nas Zonas Central, Intermediária e Periférica do município de São Paulo (classificação de Leser e Barbosa ${ }^{19}$ ) e as demais $11,0 \%$ em outros municipios da Região da Grande São Paulo. Tais informaçōes nos permitiram caracterizar a amostra estudada como pertencente, em sua maioria, a segmentos da população, da citada Região, de baixo nivel sócio-econômico.

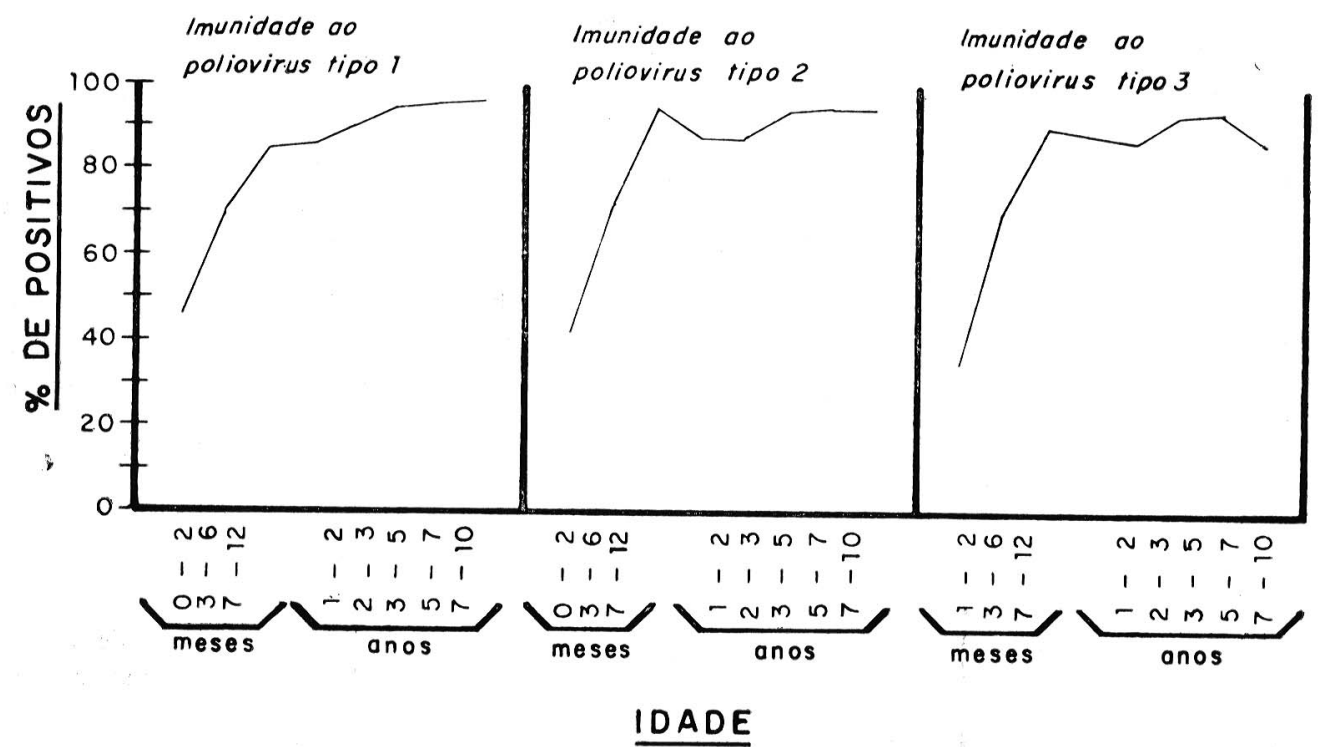

Figura: Imunidade para os très sorotipos de poliovírus, segundo a faixa etária, em crianças de zero a dez anos, atendidas em Unidades Sanitárias do Estado de São Paulo e enviadas ao Laboratório Central do Instituto Adolfo Lutz. Regiāo da Grande São Paulo, fevereiro a abril de 1982. 
BARBOSA, V, et al. Imunidade relativa à poliomielite em crianças de zero a dez anos, após o "Quarto Dia Nacional de Vacinação Contra a Poliomielite" com a vacinação oral trivalente, tipo Sabin, em área da Regiăo da Grande São Paulo, SP (Brasil), 1982. Rev. Saúae públ., S. Paulo, 18:19-29, 1984 .

\section{T A B E L A 1}

Casos e coeficientes de morbidade por poliomielite na Região da Grande São Pä̈lo, durante o período de 1970 a 1982.

\begin{tabular}{ccc}
\hline Ano & $\begin{array}{r}\text { Número de } \\
\text { casos }\end{array}$ & $\begin{array}{c}\text { Coeficiente por } \\
100.000 \text { habitantes }\end{array}$ \\
\hline 1970 & 101 & 1,2 \\
1971 & 274 & 3,2 \\
1972 & 151 & 1,6 \\
1973 & 333 & 3,5 \\
1974 & 269 & 2,7 \\
1975 & 374 & 3,6 \\
1976 & 85 & 0,7 \\
1977 & 57 & 0,5 \\
1978 & 73 & 0,6 \\
1979 & 116 & 0,8 \\
1980 & 29 & 0,2 \\
1981 & 4 & 0,03 \\
1982 & 0 & - \\
& & \\
\hline
\end{tabular}

Fonte: Centra de Informações de Saúde (CIS) da Secretaria de Estado da Saúde de Sżo Paulo.

\section{RESULTADOS}

As proporções de imunes, para cada um dos três tipos de poliovírus, nas crianças menores de 3 meses de idade, encontram-se em niveis inferiores a $50,0 \%$, enquanto que nas de 3 a 6 meses de vida essas proporções atingem cerca de $70,0 \%$ e, por fim, a partir do sétimo mês as crianças passam a apresentá-las, para cada um dos três tipos de vírus, em niveis que variam de $85,0 \%$ à $96,8 \%$ (Figura).

O estado imunitário referente à poliomielite dos grupos estudados pode ser melhor entendido ao verificarmos a Tabela 2 , onde: a) em menores de 3 meses temos $23,5 \%, 35,3 \%$ e $35,3 \%$, respectivamente, de triplo, duplo e monossuscetíveis e, além disso, $5,9 \%$ de triplo-imunes; b) em crianças de 3 a 6 meses de vida a percentagem de triplo-imunes é de $56,7 \%$, enquanto que, nos demais grupos etários, os triplos-imunes variam entre $\mathbf{7 7 , 4 \%}$ e $87,3 \%$.
Em relação à imunidade à poliomielite, segundo o número de doses de vacina recebidas pelas crianças (Tabela 3 ), observamos proporções superiores a $80,0 \%$ de triplo-imunes nos infantes de 3 a 12 meses de idade, entre as que receberam 3 ou mais doses de vacina oral trivalente, tipo Sabin; afora isso, notamos que as pertencentes à faixa etária de um a 4 anos apresentavam maiores percentagens de triplo-imunes a partir da quarta dose de vacina recebida.

Merece ênfase especial o fato de que $72,9 \%$ das crianças de 3 a 12 meses; $97,4 \%$ das de 1 a 4 anos; 95,5\% das de 5 a 7 anos; e $92,1 \%$ das 7 a 10 anos haviam recebido 3 ou mais doses de vacina oral, enquanto que $30,5 \%, 81,2 \%, 87,8 \%$ e $76,2 \%$ das crianças, na mesma ordem de idades. antes citada, receberam 5 ou mais doses dessa vacina. 


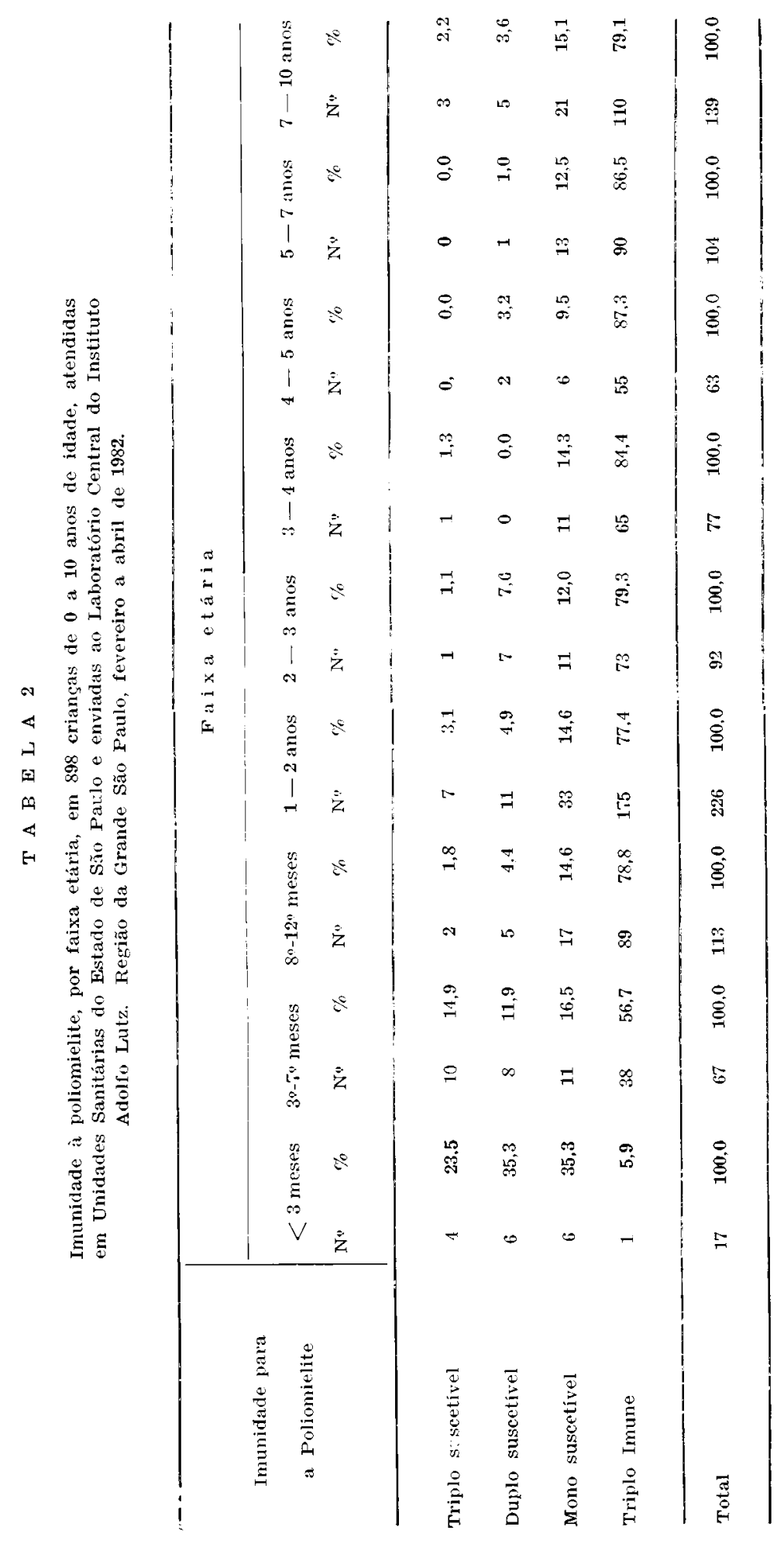




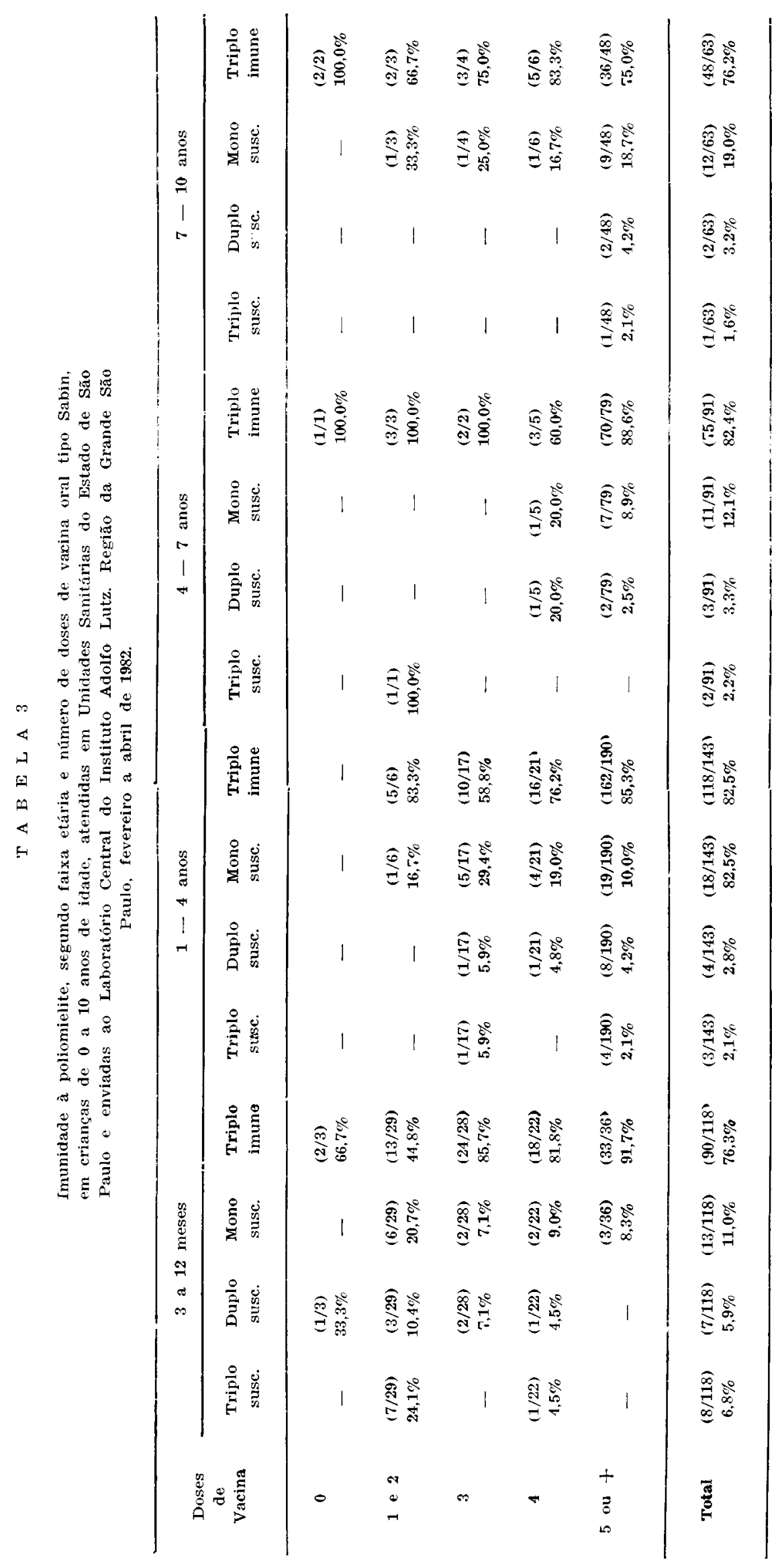


BARBOSA, V. et al. Imunidade relativa à polio mielite em crianças de zero a dez anos, após o "Quarto Dia Nacional de Vacinação Contra a Pollomielite" com a vacínação oral trivalente, tipo Sabin, em área da Região da Grande São Paulo, SP (Brasil), 1982. Rev. Saúde públ., S. Paulo, 18:19-29, 1984 .

\section{DISCUSSÃO}

A alta proporção de imunes para os três sorotipos de poliovirus entre as crianças estudadas, cotejada com a acentuada queda da incidência de poliomielite na Região da Grande São Paulo, desde $1980^{39}$, vem, sem dúvida, realçar o acerto dos "Dia Nacional de Vacinação Contra a Poliomielite" aplicados em nosso país, a partir daquele ano, contra a doença de Heine-Medin.

Levantamentos sorológicos para averiguação da imunidade à poliomielite realizados em alguns pontos do pais, inclusive em área da Região da Grande São Paulo, em periodo anterior a introdução, em 1964 3 , da imunização de rotina contra essa virose - com vacina oral trivalente de vírus vivo atenuado - revelaram, aproximadamente, $80,0 \%$ de triplo-imunes em crianças a partir do quarto ano de vida 1,20,26,27,36, e de cerca de $5,0 \%$ a $14,0 \%$ em menores de um ano, mostrando, assim, a vulnerabilidade dessa última faixa etária, atribuída à precocidade com que se dá, em nosso meio, a infecção por poliovírus, especialmente em determinados segmentos sociais 28,39 .

Confrontando estes resultados e os anteriores obtidos por Barbosa e col. ${ }^{4}$, em 1973, com os dados publicados por Melnick e col. ${ }^{25}$, referentes ao estado imunitário de crianças contra a poliomielite em Houston (USA) em 1963, logo após uma campanha de imunização em massa com a vacina tipo Sabin e, em 1968, após terem se passado 5 anos de utilização exclusiva de vacinação rotineira, verificamos um comportamento, até certo ponto, superponível. Concordam esses autores quanto ao acentuado aumento na proporção de imunes e na existência de um residuo de suscetiveis nos menores de um ano de vida, especialmente entre os $3^{\circ}$ e $9^{\circ}$ meses de vida.

Melnick e col.25, naquela oportunidade, salientaram que essa lacuna imunitária no primeiro ano de vida, ainda remanescente após a campanha de vacinação em massa, permite, em se tratando de população de baixo nivel sócio-econômico, explicar a ocorrência de surtos epidêmicos de poliomielite.

O residuo de crianças suscetíveis, antes citado, verificado na presente pesquisa, poderia, ao que tudo indica, explicar a tendência do aumento relativo dos casos de poliomielite em menores de 6 meses, em 1981, se comparado com os dos anos anteriores, tanto na Região da Grande São Paulo como nos dados globais para o nosso país ${ }^{31,39}$.

Cumpre salientar a alta proporçāo de triplo-imunes entre as nossas crianças maiores de 5 anos, grupo excluído da população alvo para os "Dia Nacional de Vacinação Contra a Poliomielite", mas também vacinado em significativa proporção. Este resultado adquire importância quando o comparamos com os obtidos em pesquisas soro-epidemiológicas realizadas, na mesma região, em épocas anteriores 4,38 . Tal fato sugere que a ampla disseminação local do vírus atenuado, decorrente da imunização em massa, determinou infeç̧ão em contatos não vacinados. Não se deve, porém, desconhecer o fato, acima referido, das crianças mainres de 5 anos terem sido imunizadas nos "Dia Nacional de Vacinação Contra a Poliomielite".

De tudo que foi exposto evidencia-se, seguramente, a necessidade de serem estudados esquemas alternativos para a vacinaçāo de rotina, entre nós, visando a permitir ü manutenção dos niveis atuais de incidência da poliomielite. No futuro, caso venham a ser suspensas as campanhas de vacinação $\mathrm{cm}$ massa em nosso país, deverá ser escolhida a aplicação de um esquema de imunização rotineira que não permita a ampliação da lacuna imunitária observada na faixa etária de menores de um ano e, particularmente, no primeiro semestre de vida. Tal medida poderá evitar a ocorrência de surtos epidêmicos, como os que têm sido observados em paises de- 
BARBOSA, V. et al. Imunidade relativa à poliomielite em crianças de zero a dez anos, após o "Quarto Dia Nacional de Vacinação Contra a Poliomielite" com a vacinação oral trivalente, tipo Sabin, em área da Regiāo da Grande Sào Paulo, SP (Brasil), 1982. Rev. Saúde júbl., S. Paulo, 18:19-29, 1984 .

senvolvidos que, há muito tempo, alcançaram o controle dessa virose $\overline{i, 11,13}$.

Vale a pena destacar a introdução, entre os esquemas alternativos de vacinação de rotina, da imunização de gestantes com virus inativado ${ }^{14,21}$ que, por outro lado, se associado à vacina anti-tetânica, apresentaria óbvias vantagens administrativas e operacionais. A presença de altos títulos de anticorpos neutralizantes, à vacina Salk, em individuos anteriormente infectados com poliovirus "selvagem" ou "vacinal"zó é, por si só, argumento ponderável e favorável a essa alternativa, uma vez que ampliaria o periodo de vigência dos anticorpos maternos nas crianças em seus primeiros meses de vida.

Outro esquema de imunização discutido, em pormenores, em diversas publicações, diz respeito à vacinação do recém-nascido, com vírus vivo atenuado $8,18,29,30,34,39$. Merece ainda especial atenção os estudos recentemente efetuados, também nesse sentido, e aparentemente bem sucedidos, em regiōes subdesenvolvidas que imunizam os menores de um ano de idade com a vacina oral trivalente, tipo Sabin, aos 2,4 e 6 meses, sendo a primeira dessas 3 doses administradas simultaneamente com a vacina triplice associada a Salk — vacina quádrupla 16.23:24.

Os três esquemas alternativos de vacinação de rotina apresentados merecem estudos de campo para a adequada avaliação da eficiência e eficácia de cada um deles.

Em relação às doses de vacina oral tipo Sabin recebidas pelas crianças por nós pesquisadas, cumpre salientar a elevada proporção das que receberam 5 ou mais doses, o que poderia explicar, em boa parte, a reduzida quantidade de suscetiveis observada $\mathbf{5 , 1 6}$.

Finalmente, no que tange ao estado imunitário dessas crianças, em relação ao número de doses de vacina recebidas, chama a atençāo, no grupo etário de 3 a 12 meses, a percentagem de $85,2 \%$ de triplo-imunes observada entre as crianças que receberam somente 3 doses; isto, porque sabemos que para os paises subtropicais são preconizadas $\checkmark$ aplicaçôes de vacina tipo Sabin para se alcançar bons resultados ${ }^{5,16}$. Tal fato poderia, ao nosso ver, ser explicado pela menor possibilidade de quebra da "cadeia de frio" durante os "Dia Nacional de Vacinação Contra a Poliomielite", pela ampla disseminação do vírus vacinal, acompanhados da existência de condições ambientais propicias à infecção precoce pelos poliovírus e da aplicação de 3 doses dessa vacina em periodo relativamente curto, diminuindo, assim, a possibilidade de interferência determinada por outros enterovírus que, como tem sido mostrado, são altamente prevalentes entre nós $9,10,12,37$.

\section{CONCLUSŌES}

- As crianças estudadas apresentaram-se, em alta proporção, imunes aos três sorotipos de poliovirus.

- Verificou-se ainda, apesar dos quatro "Dia Nacional de Vacinação Contra a Poliomielite" em 1980 e 1981, uma lacuna imunitária nos menores de um ano, especialmente naqueles com idade inferior a 7 meses de vida.

- Não se deram a ver diferenças importantes na proporção de imunes, segundo o sorotipo de poliovirus considerado.

- Existe a necessidade de um alerta constante e permanente em relação à ocorrência de possiveis surtos epidêmicos em segmentos de nossa população mais vulneráveis à poliomielite, particularmente entre as crianças menores de um ano. Impõe-se a necessidade da vigilância epidemiológica da poliomielite ativa e contínua, por meio de estudos soro-epidemiológicos, na atual fase de controle dessa virose em nosso pais. 
BARBOSA, V, et al. Imunidade relativa à poliomielite en crianças de zero a dez anos, após o "Quarto Dia Nacional de Vacinaçăo Contra a Poliomielite" com a vacinaçăo oral trivalente, típo Sabin, em área da Regiăo da Grande Sảo Paulo, SP (Brasil), 1982. Rev. Saúde públ., S. Paulo, 18:19-29, 1984 .

\section{CONSIDERAÇÖES FINAIS}

Encontramo-nos em plena fase de vigilância epidemiológica pós-controle da poliomielite, obtida pelos primeiros quatro "Dia Nacional de Vacinação Contra a Poliomielite" nos anos de 1980 e 1981. Portanto, a Região da Grande São Paulo já está a necessitar, seguramente, novas táticas e métodos de aferição do atual comportamento da paralisia infantil, como vimos no decorrer dos capitulos de "Resultados e Discussão" deste trabalho e que, anteriormente, em outro trabalho ${ }^{6}$, já tinham sido sugeridas. Sobrelevam-se, entre elas, a realização de estudos soro-epidemiológicos na população infantil dessa Região, sobretudo de zero a 4 anos de idade inclusive, visando a fornecer subsídios às autoridades sanitárias para um diagnóstico mais preciso da nossa realidade, e que também possa, partindo daí, planejarem sua conduta em relação à futura manutenção de eliminação da doença entre nós.

Para a execução de estudos dessa natureza duas seriam as condutas a serem seguidas: 1) realização de um amplo estudo soro-epidemiológico, por amostragem, num mesmo período de tempo, de toda a população infantil da Região da Grande São Paulo, no sentido de se verificar o estado imuni- tário dessa população; 2) realização de vários estudos soro-epidemiológicos, com o mesmo propósito antes citado, em diferentes áreas dessa Região, em diferentes períodos de tempo, cujo conjunto poderia fornecer uma idéia aceitável sobre a realidade do estado imunitário da população de zero a 4 anos inclusive. Isto serviria de fundamento para o diagnóstico epidemiológico atual dessa virose e a tomada de providências técnico-administrativas e operacionais, na oportunidade, para a manutenção do seu controle.

Infelizmente, obstáculos predominantemente administrativos e operacionais vêm dificultando a execução desses estudos antes referidos. Este fato, aliado à existência de poucos trabalhos publicados após o primeiro "Dia Nacional de Vacinação Contra a Poliomielite" $6,31,39$, nos levou a elaborar este trabalho, especificamente dirigido aos efeitos sobre o comportamento do estado imunitário da população infantil suscetivel, em virtude da realização dos quatro primeiros "Dia Nacional de Vacinação Contra a Poliomielite", o qual será seguido, segundo nossa pretensão, de novos estudos com a mesmá finalidade, de modo a oferecer uma boa e aceitável idéia da situação epidemiológica da poliomielite em nosso meio.

BARBOSA, V. et al. [Relative immunity to poliomyelitis in children up to ten years of age, after the "4th National Antipoliomyelitis Vaccination Day" with trivalent oral Sabin vaccine, in Greater S. Paulo (Brazil), 1982], Rev. Saúde públ., S. Paulo, 18:19-29, 1984

ABSTRACT: An epidemiological analysis was carried out on 898 children, in order to study the immune response to polioviruses 1,2 and 3 by means of the measurement of neutralising antibodies. Information was obtained from $522(58.1 \%)$ of the children with regard to their vaccinal position by examination of the observations recorded on the individual vaccination certificates. In this subgroup the immune status in relation to number of Sabin type oral vaccine doses was analysed. The analysis demonstrated a high proportion of protected children for three types of polivirus, but also an immune response failure among the children of less than one year old, mainly during the first semester after birth. There were no relevant differences in relation to the proportion of protected individuals according to the considered serotype. The need for persistent and continuous vigilance in view of the possible occurence of epidemic outbreaks in high risk segments of the population, principally among children under one year of age was emphasized.

UNITERMS: Poliomyelitis. Soroepidemiological survey. Prophylaxis. Epidemiological surveillance. 
BARBOSA, V. et al. Imunidade relativa à poliomielite em crianças de zero a dez anos, após 0 "Quarto Dia Nacional de Vacinação Contra a Poliomielite" com a vacinação oral trivalente, tipo Sabin, em área da Reglăo da Grande Săo Paulo, SP (Brasil), 1982. Rev. Saúde públ., S. Paulo, 18:19-29, 1984 .

\section{REFERENCIAS BIBLIOGRAFICAS}

1. ALMEIDA, J.O.; WINSSER, J., SANCHES, A. \& VIEIRA, R.R. Nivel de anticorpos antipoliomielite em crianças de Ribeirão Preto. Rev. paul. Med, 52:283-9, 1958.

2. BARBOSA, V. Contribuição para o conhecimento da epidemiologia da poliomielite no município de São Paulo. São Paulo, 1963. [Tese de Doutorado - Faculdade de Higiene e Saúde Pública da USP].

3. BARBOSA, V. Estudo atualizado da poliomielite no município de São Paulo. Rev. Saúde públ., S. Paulo, 2:68-80, 1968.

4. BARBOSA, V. \& STEWIEN, K.E. Estado imunitário relativo à poliomielite das crianças de $0-12$ anos, residentes no municipio de são Paulo, Brasil e assistidas pelo Hospital Menino Jesus. Rev. Saúde públ., S. Paulo, $9: 137-53,1975$.

5. BARBOSA, V.; STEWIEN, K.E.; LIMA, O.S. \& OSIRO, K. Nivel de imunidade contra a poliomielite em um grupo de crianças vacinadas de acordo com o calendário oficial de imunização (São Paulo, Brasil). Rev. Saúde públ., S. Paulo, 12:326-32, 1978.

6. BARBOSA, V. \& STEWIEN, K. E. Aspectos de importancia para a vigilancia epidemiológica da poliomielite na cidade de São Paulo, Brasil. Rev. Saude públ., S. Paulo, 14:557-68, 1980.

7. BOTTIGER, M.; MELLIN, P.; ROMANUS, V.; SODERSTROM, H.; WESSLEN, T. \& ZEIPEL, G.V. - Epidemiological events surrounding a paralitic case of poliomyelitis in Sweden. Bull. Wld Hlth Org., 57:99-103, 1979.

8. CAMPILLO, S.C.; HERNANDEZ, A.O.; MACIAS, J.M. \& NAVA, S.E. Immunization of newborn children with living oral trivalent poliovirus vaccine. J. Bact., 84:446-50, 1962.

9. CANDEIAS, J.A.N. Isolamento e identificacão intratípica de cepas de poliovirus associadas com a administração de vacina Sabin. Rev. Saúde públ., S. Paulo, 3:183-201, 1969.

10. CANDEIAS, J.A.N.; IARIA, S.T.; CHRISTOVAO, D.A.; SCHMID, A.W.; TAUNAY, A.E. \& COTILLO, Z.L.G. Pesquisa de enterobacteriáceas e enterovirus em crianças normais e com quadros diarréicos agudos. Rev. saúde públ., $\mathbf{S}$. Paulo, 2:194-206, 1968.
11. CENTER FOR DISEASE CONTROL: Poliomyelitis Survellance, Summary 1980-1981. Atlanta, Ga., 1982.

12. CHRISTOVAO, D.A.; CANDEIAS, J.A.N. \& IARIA, S.T. Condições sanitárias das águas de irrigação de hortas do município de São Paulo. II - Isolamento de vírus entéricos. Rev. Saúde públ., $\mathrm{S}$. Paulo, 1:12-7, 1967.

13. COOD, A.A. \& WHITE, E. Protection against poliomyelitis. The Lancet, $2: 1.078$, 1977.

14 GUASChINo, s. Per una protezione antipoliomielitica effetiva e precoce del lattente attraverso la vaccinoprofilassi in gravidanza. Min. med., 60:1,461-4, 1969

15. HORSTAMANN, D.M. Control of poliomyelitis: a continuing paradox. $J$. infect. Dis., 146:540-51, 1982.

16. KRISHNAN, $R$. et al. Immune response of infants in tropics to infectable polio vaccine. Brit. med. J., 284:164, 1982.

17. LACERDA, J.P.G.; VIEIRA, E.F.L.; MARTIN, B.S. \& GIUSTI, L.S. Isolamento e identifiacção de poliovírus em São Paulo de 1967 a 1970. Rev. Inst. Adolfo Lutz, 31:21-5, 1971.

18. LEPOW, M.L.; WARREN, R.J.; GRAY, N.; INGRAN, V.G. \& ROBBINS, F.C. Effect of Sabin type I poliomyelitis vaccine administered by mouth to newborn infants. New Engl. J. Med., 264:1.071-8, 1961.

19. LESER, W.S.P. \& BARBOSA, V. Relacionamento de certas características populacionais com a mortalidade infantil no município de Săo Paulo, de 1950 a 1970. Probl. bras., S. Paulo, 10:17-23, 1972.

20. MARTINS DA SILVA, M. \& SYVERTON, J.T. Poliomyelitis survey in Rio de Janeiro. Publ. Hlth Rep., 71:395-8, 1956.

21. MARTINS DA SILVA, M.; PREM, K.A.; JOHNSON, E.A.; MCKELVEY, J.L. \& SYVERTON, J.T. Response of pregnant-women and their infants to poliomielitis vaccine. J. Amer. med. Ass., 168:1_5, 1958.

22. MELNICK, J.L. Ventajas e inconvenientes de las vacinas antipoliomielíticas elaboradas com virus vivos e com virus muertos. Bol. ofic. sanit. panamer., 88:507-27, 1980. 
BARBOSA, V. et al. Imunidade relativa à poliomielite em crianças de zero a dez anos, após o "Quarto Dia Nacional de Vacinação Contra a Pollomielite" com a vacinaçz̃o oral trivalente, tipo Sabin, em área da Região da Grande São Paulo, SP (Brasil), 1982. Rev. Saúde públ., S. Paulo, 18:19-29, 1984.

23. MELNICK, J.L. Combined use of live and Killed vaccines to control poliomyelitis in tropical areas; International Symposium on Reassessment of Inativated Poliomyelitis Vaccine, Bilthoven, 1980. Develop. biol. Stand, 47:265-73, 1981.

24. MELNICK, J.L. Toward eradication of poliomyelitis by combined use of Killed and live poliovirus vaccine. Cardiovasc. Res. Center Bull., 20:49-59, 1982.

25. MFLNICK, J.L.; BURKHARDT, M. ; TABER, L.H. \& ERCKMAN, P. N. Developing pag in immunity to pollomyelitis in an trban area. J. Amer. med. Ass., 209:1.181-5, 1969.

26. MOURA, R.A.A. Resultados de uma campasha de vacinação em massa contra a poliomielite em comunidade do Estado de São Paulo: importancia do levantamento sorológico. São Paulo, 1970. [Tese de Doutorado - Faculdade de Ciências Farmacêticas USP].

27. MOURA, R.A.A.; CAMPOS, L.G.; MARTINEZ, C.H.O.; MILANO, E.A. \& PIZA, J.T. Avaliação dos resultados de uma campanha de vacinação contra a poliomielite em São Paulo, Brasil. II. Estado imunitário da população antes da vacinação. Rev. Inst. Adolfo Lutz, 22/23:81-6, 1962/63.

28. NEVES, W.E. Alguns aspectos da poliomielite no primeiro semestre de vida: estudo de 241 casos, São Paulo, 1972. [Tese de Doutorado - Faculdade de Medicina USP].

29. NEVES, W.E.; RODRIGUES, M.C. ; KIPNIS, J.; CARVALHO, R.P.S. \& AMATO NETO, V. Vacinação antipoliomielítica, tipo Sabin, em crianças com um e três meses de idade. Rev. Inst. Med. trop. S. Paulo, $10: 376-82,1968$.

30. PAGANO, J.S.; PLOTKIN, S.A. \& KOPROWSKI, H. Variations in the responses of infants to living attenuated poliovirus vaccines. N.ew Engl. J. Med, 264:155-63, 1961.

31. POLIOMIELITE, Brasil: 1981. Bol. epidemiol., Rio de Janeiro, 14:154-60, 1982.
32. ROSENBAUM, M.J.; PHILLIPS, I.A.; SULLIVAN, E.J.; EDWARDS, E.A. \& MILLER, I.F. - A simplified method for virus tissue culture procedures in microtitration plates. Proc. Soc. exp. Biol., $113: 224-9,1963$.

33. SABIN, A.B.; RAMOS-ALVAREZ, M.; ALVAREZ-AMEZQUITA, J.; PELON, W.; MICHAELS, R.H.; SPIGLAND, I.; KOCH, M.A. \& BARNES, J.M. Live orally given poliovirus vaccine. Effects of rapid mass immunization on population linder conditions of massive enteric infection with other viruses, J. Amer. med. Ass, $173: 1.521-6$, 1960.

34. SABIN, A.B.; MICHAELS, R.H.; ZIRING, P.; KRUGMAN, S. \& WARREN, J. Effect of oral poliovirus vaccine in newborn children. II. Intestinal resistence and antibody at 6 months in children fed type $I$ vaccine at i birth. Pediatrics, 31:641-50, 1963.

35. SALK, J. \& SALK, D. Control of influenza and poliomyelitis with Killed virus vaccines. Science, 195:834-47, 1977.

36. SILVA, N.N. Imunidade natural à poliomielite em Porto Alegre, Brasil. Hospital, Rio de Janeiro, 58:109-18, 1960.

37. SCHMID, A.W.; STEWIEN, K.E. \& CANDEIAS, J.A.N. Evidenciação de vírus patogênicos humanos em filés de peixe. Rev. Saúde públ., S. Paulo, 11:405-10, 1977.

38. STEWIEN, K.E.; BARBOSA, V. \& ROSENBURG, C.P. Niveis de imunidade contra poliomielite em uma amostra de escolares no municipio de São Paulo, Brasil. Rev. Saúde públ., S. Pa:.lo, $11: 270-8,1977$.

39. WALDMAN, E.A.; BARBOSA, V.; FUGITA, M.; WALDMAN, C.C.S. \& LACERDA, J.P.G. Aspectos epidemiológicos e imunitários da poliomielite em crianças menores de um ano em area da Região da Grande São Paulo, Brasil. Rev. Saúde públ., S. Paulo, 17:9-22, 1983.

Recebido para publicacáa em 30/08/1983 Aprovado para publicaç̃o em \$4/10/1983 